\title{
Da janela do Clarimundo: a condição do intelectual em Erico Verissimo
}

Marcos Scheffel

RESUMO: Em Caminhos cruzados (1934), segundo romance de Erico Verissimo, várias personagens transitam pela capital gaúcha. Uma delas problematiza dilemas da intelectualidade brasileira: o professor Clarimundo Roxo. Este artigo tem por objetivo debater a função desempenhada por essa personagem no que se refere à representação do intelectual e seus dilemas na obra de Erico Verissimo.

PALAVRAS-CHAVE: Erico Verissimo; Caminhos cruzados; o intelectual de 30; o escritor de 30

\begin{abstract}
In Caminhos cruzados (1934), the second novel written by Erico Verissimo, many different characters wander about the city of Porto Alegre. One of them is responsible for questioning dilemmas of the Brazilian intelligentsia: the school teacher Clarimundo Roxo. The aim of this paper is to discuss the role played by Clarimundo in relation to the representation of the man of letters and his dilemmas in the works of Erico Verissimo.
\end{abstract}

KEYWORDS: Erico Verissimo; Caminhos cruzados; 1930s intelligentsia; 1930s writer 
Eu nada entendo da questão social.

Eu faço parte dela, simplesmente...

E sei apenas do meu próprio mal, Que não é bem o mal de toda gente.

Mario Quintana ${ }^{1}$

Em Erico Verissimo: realismo e sociedade, Flávio Loureiro Chaves promoveu um importante estudo sobre a obra do autor de O tempo e o vento. ${ }^{2}$ Com um referencial teórico baseado na sociologia do romance, em especial Lucien Goldmann e Georg Lukács, Chaves centrava atenção ao chamado "ciclo de Porto Alegre" - formado por Música ao longe (1934), Um lugar ao sol (1936), Olhai os lírios do campo (1938), Saga (1940) e O resto é silêncio (1943) e pelos dois romances de estreia de Erico Verissimo: Clarissa (1933) e Caminhos cruzados (1934). Nesse período, o romancista gaúcho teria enfrentado seus principais dilemas ideológicos e formais. No plano ideológico, Erico teria definido um campo de ação, pois mesmo em seus romances urbanos apareciam críticas ao caudilhismo que marcou a história do Rio Grande do Sul. No plano formal, o autor teria experimentado técnicas ficcionais, como a do contraponto, ${ }^{3}$ que lhe propiciou, de acordo com Chaves, uma visão do "universo moderno, fragmentado, nas cisões ideológicas, na crise da individualidade, na falência das relações transindividuais, na perda da ideia de centralidade, em tudo aquilo enfim que caracterizava a vida urbana reificada". ${ }^{4}$

Chaves detectava ainda a questão da escrita e a condição do escritor no Brasil, como um dos temas recorrentes na produção de Verissimo. Em Caminhos cruzados, por exemplo, a questão da escrita e do fazer literário era debatida com a presença do par Noel e Fernanda. O primeiro, proveniente de uma família de classe média, é fascinado por Katherine Mansfield e está convencido de que a literatura deveria falar de mundos imaginários, que propiciassem uma fuga da melancolia da vida. Por sua vez,

1. Quintana, Mário. Quintana de Bolso - Rua dos Cataventos \& outros poemas. Porto Alegre/Rs: LP\&M, 2007, p. 10.

2. Chaves, Flávio Loureiro. Erico Verissimo: realismo e sociedade. Porto Alegre/Rs: Globo, Instituto Estadual do Livro, Secretaria de Educação e Cultura do Rio Grande do Sul, 1976.

3. Erico Verissimo traduziu do inglês para o português o romance Point Counter Point, de Aldous Huxley, surgindo daí o interesse pelo contraponto. A primeira edição em português é de 1934 .

4. Chaves, Flávio Loureiro. Op. cit., p. 17. 
Fernanda, vista por muitos como uma espécie de alter ego do autor, 5 postulava para Noel que a literatura deveria concentrar-se nos fatos do dia a dia e fornecia ao amigo uma sugestão de romance: a história de um pobre homem tuberculoso e da precária condição financeira dele e de sua família. Para Antonio Candido, a fala de Fernanda "parece-nos entrar no cerne da estética anestética dos anos 1930". Já para Noel escrever sobre a realidade social seria "uma traição à arte". 6

Como vemos nas obras de Chaves e Candido, a importância desse par já foi apontada, além de ter sido referendada pelo próprio autor. Fernanda e Noel, a exemplo de outras personagens, apareceriam ainda em Saga (1940), livro em que dividem as ações com Vasco e Clarissa - personagens de romances anteriores publicados pela livraria do Globo. A presença recorrente dessas personagens em outras obras demonstra uma preferência do romancista por personagens jovens e sonhadoras, em detrimento de personagens com quarenta anos ou mais, e de personagens caricatas. Quanto às personagens mais velhas, o autor comenta que à época da publicação de Clarissa "considerava velho um homem de quarenta anos".

Quanto à caricatura, Erico demonstra restrições ao uso da técnica na construção de algumas de suas personagens, como no prefácio escrito em 1964 para uma nova edição de Caminhos cruzados: "Que dizer das personagens?/ Creio que têm a força e ao mesmo tempo a fraqueza da caricatura”. Talvez Erico estivesse, no momento da escrita dos prefácios, quase três décadas depois, afinado com percepções críticas como as de Lúcia Miguel Pereira, segundo a qual a sátira e o realismo seriam irredutíveis:

Na verdadeira sátira há um fator idealista, uma transposição da realidade que não lhe permite sofrer contato com a observação direta dos fatos e dos caracteres sem se trans-

5. Em carta a Erico Verissimo, Jorge Amado louvava a construção das personagens e via em Fernanda a projeção do autor (AmAdo, Jorge. In: Erico Verissimo: o escritor no tempo 1905-199o. Organização de Maria da Glória Bordini. Porto Alegre/Rs: Secretaria Municipal de Cultura, 1990). Constatação semelhante é a de Silviano Santiago: "Parece que o alter ego do romancista é Fernanda" (SAntiago, Silviano. "A estrutura musical do romance - o caso Erico Verissimo". In: Nas malhas da letra. São Paulo: Companhia das Letras, 1989, p. 157).

6. CANDIDo, Antonio. "Erico Verissimo: de trinta a setenta". In: Recortes. Rio de Janeiro: Ouro sobre Azul, 2004, pp. 75-6.

7. Verissimo, Erico. Clarissa. 51. ed. São Paulo: Globo, 1997, p. XVII.

8. Id. Caminhos cruzados. 31. ed. São Paulo: Globo, 1995. 
formar em caricatura superficial e vulgar, sem restringir o seu alcance. A inumanidade da caricatura é que se choca com o senso poético. ${ }^{9}$

Essa constatação - feita por uma renomada crítica e romancista da mesma geração do autor gaúcho ${ }^{10}$ - demonstra um impasse da estética realista quanto ao uso da caricatura: o caráter deformador e pouco humanista da técnica ficcional. Nessa mesma análise, Pereira citava, em inglês, trechos de Aspects of the Novel, de E. M. Forster, que condenavam a cópia de uma personagem do mundo real. ${ }^{11}$

Provavelmente, Erico teve contato com as teorias de Forster no seu trânsito pelos Estados Unidos nas décadas de 40 e 50. Nos prefácios de Clarissa e de Música ao longe, ambos datados de 1961, Erico volta a julgar de maneira negativa o uso da caricatura: "Amaro me parece uma personagem demasiadamente esquemática".12 / "No retrato de Paulo Madrigal, o caixeiro-viajante-poeta, a mão do caricaturista voltou a calcar fundo". ${ }^{13}$ Como se vê, as restrições a personagens caricatas aconteceram a posteriori, tendo sido motivadas por comentários críticos desfavoráveis a certas personagens ou por uma evolução de sua técnica ficcional, que o levava a rejeitar criações ficcionais anteriores. ${ }^{14}$ Parece que o prazo de duração ou os efeitos obtidos com essas personagens caricatas eram válidos por apenas um romance. Daí a não reutilização dessas personagens em outros romances.

Ao comentar as diferenças entre seu primeiro romance e Caminhos cruzados, Erico Verissimo afirma que "Clarissa foi a oportunidade do poeta", que o livro fora com-

9. Pereira, Lúcia Miguel. História da literatura brasileira: prosa de ficção: de 1870 a 1920. Belo Horizonte: Itatiaia; São Paulo: Edusp, 1988, pp. 293-4. Os comentários de Lúcia Miguel Pereira eram referentes a Recordações do escrivão Isaías Caminha, de Lima Barreto, que teria apresentado esse problema de construção ficcional.

10. Lúcia Miguel Pereira publicara Em surdina, seu primeiro romance, em 1933, pela Ariel. O livro é considerado "o mais importante romance publicado por um escritor católico em 1933” (BuENO, Luís, Uma história do romance de 30. São Paulo: Edusp; Campinas: Editora da Unicamp, 2006, p. 200).

11. Pereira, Lúcia Miguel. Op. cit., pp. 293-4.

12. Verissimo, Erico. Clarissa, cit., p. XviI.

13. Id. Música ao longe. 39. ed. São Paulo: Globo, 1997. s/n.

14. É interessante a leitura de Caminhos cruzados promovida por Dante Costa para o Boletim de Ariel. O crítico associa a técnica ficcional do romance a uma visão aérea da cidade e das personagens pelo narrador. Essa leitura sugere que o narrador do romance adota um ponto de vista distanciado do mundo, como o proposto pelo professor Clarimundo para o seu futuro livro (CostA, Dante. "Caminhos cruzados". Boletim de Ariel, Rio de Janeiro, n. 11, pp. 300-3-1, ago. 1935). 
posto por "instantes pictóricos, numa sucessão de haicais e aquarelas", enquanto que no segundo livro dera "carta branca ao satirista". ${ }^{15}$ Observa-se nesses prefácios publicados em 1961 que há um movimento de Erico em negar aquilo que considerava inferior em sua ficção, usando a primeira pessoa para marcar as condições de escrita, quase sempre precárias devido aos inúmeros afazeres para viver como escritor, e a terceira pessoa para apontar as influências e os problemas da produção desse período. Assim: "O poeta que escrevera Clarissa estava um tanto perplexo em face do caricaturista que traçara a carvão e sarcasmos retratos como os de Dodó, Leitão Leiria e Armênio Albuquerque". ${ }^{16}$

Nesse jogo de autocrítica, o caso do professor Clarimundo Roxo parece bastante emblemático, pois essa personagem caricata reúne algumas das principais contradições e impasses da intelectualidade brasileira na década de 30. É com ele que se abre e se fecha a narrativa de Caminhos cruzados, formando uma espécie de moldura para a história narrada. Quando o trabalho do autor real (Erico Verissimo) se encerra, inicia-se o trabalho do autor ficcional (Clarimundo Roxo), que começa a escrever seu próprio livro, trabalho que vinha sendo anunciado e cancelado desde o início da narrativa. Não se sabe ao certo se esse projeto autoral de Clarimundo será levado a cabo, se será publicado, se terá leitores, se será criticado. Sabe-se que o livro é iniciado de maneira pouco convencional: pelo prefácio e sem que o restante da obra estivesse pronto. Assim, a justificativa do projeto autoral vem antes da escrita do próprio livro.

Esse projeto autoral-ficcional que emoldura as ações das demais personagens de Caminhos cruzados põe em cena a posição do intelectual brasileiro naquela década: não integrado aos extratos populares e prestando serviços à burguesia que lhe garante uma sobrevivência precária. Quanto aos impasses e contradições da intelectualidade perceptíveis na trajetória de Clarimundo Roxo, podem-se destacar: 1) a impossibilidade de diálogo com as camadas mais baixas e mesmo com os setores médios da sociedade; 2) as diversas frentes de sua profissão para garantir seu sustento; 3) a relação problemática com os avanços tecnológicos.

A seguir, analiso esses três aspectos da trajetória de Clarimundo Roxo, traçando comparações com outras personagens do universo ficcional de Erico Verissimo, em especial em seus três primeiros romances, procurando indicar como essa personagem pouco analisada problematizava algumas questões sobre o papel do intelectual na década de 30 .

15. Verissimo, Erico. Clarissa, cit., p. XiII.

16. Id., Caminhos cruzados, cit., p. s/n. 
Com o advento da cidade letrada, ${ }^{17} \mathrm{o}$ cargo de professor passou a dividir com o funcionalismo público, com o jornalismo e com a política uma das possibilidades de ocupação para os candidatos às carreiras das letras, compondo, por assim dizer, a nossa intelligentsia. Num país de pouco leitores, viver somente de literatura sempre foi uma tarefa das mais difíceis. Nesse cenário, a função de professor foi uma daquelas carreiras que garantiram o sustento de muitos escritores, além de revestir o indivíduo de certa relevância social.

Em Caminhos cruzados, a diferenciação social de Clarimundo é marcada pela posição espacial ocupada pela personagem: sua casa está mais elevada em relação à dos demais moradores da travessa das Acácias, permitindo-lhe uma visão privilegiada da rotina dos seus vizinhos. Do ponto de vista espacial, o professor é como o próprio personagem-narrador do livro que planeja escrever, que pode observar do alto e à distância a rotina de todos, como revela o narrador onisciente de Caminhos cruzados:

A sua obra... Agora ele já não enxerga mais a paisagem. O mundo objetivo se esvaeceu misteriosamente. Os olhos do professor estão fitos na fachada amarela da casa fronteira, mas o que ele vê agora são as suas próprias teorias e ideias. Imagina o livro já impresso... Sorri, exterior e interiormente. O leitor (a palavra leitor corresponde, na mente de Clarimundo, à imagem dum homem debruçado sobre um livro aberto: e esse homem extraordinário! - é sempre o sapateiro Fiorello) - o leitor vai se ver diante dum assunto inédito, diferente, original. Tomemos por exemplo uma estrela remotíssima; digamos... Sírio. Coloquemos lá um ser dotado da faculdade do raciocínio e senhor de um telescópio possante com o qual possa enxergar a Terra... Como seria a visão do mundo e da vida surpreendida do ângulo desse observador privilegiado ${ }^{28}$

O homem de Sírio a tudo observa com seu potente telescópio e revela verdades inalcançáveis para o homem comum. Clarimundo quer revelar no seu livro as grandes verdades, porém ignora fatos corriqueiros; por exemplo, ele não se dá conta de que numa das casas que observa mora um de seus alunos, Pedrinho, o irmão de Fernanda.

17. Rama, Angel. Las máscaras democráticas del modernismo. Montevideo: Fundación Ángel Rama, 1985.

18. Verissimo, Erico. Caminhos cruzados, cit., p. 39. 
Ele está numa espécie de torre de marfim e os pequenos dramas do dia a dia passam longe de sua percepção. Sem se dar conta, põe-se a planejar seu livro "longe do estéril turbilhão da rua.".

Duas características assinaladas acima - a revelação de verdades únicas e a distância em relação ao povo - foram traços marcantes da poesia produzida no Brasil no início do século xx pelo parnasianismo e pelo simbolismo. Pode-se dizer que Clarimundo tem outras características ligadas ao academicismo que marcou nosso início de século: o purismo linguístico perceptível nas preocupações unicamente gramaticais de suas aulas de português, inglês, francês, latim e uma concepção ilustrada de conhecimento. É essa concepção ilustrada que faz Clarimundo tentar expor seus conhecimentos para pessoas que não o entendem, quando cita Einstein para seus alunos, quando entedia o entregador de pães com teoria da gravidade ou quando tenta explicar para o sapateiro italiano Fiorello quem era o homem de Sírio.

Como um bom professor, ele transmite conhecimentos superiores a uma audiência passiva, que dificilmente poderia acessá-los sem a ajuda do mestre. Além disso, Clarimundo cumpre outra função típica de um professor que se limita a transmitir conhecimentos: apontar erros, corrigir. Ele só consegue ver na fala dos seus alunos erros de gramática. É a única coisa que lhe chama a atenção. Nada da fala do Outro lhe interessa. Suas aulas são marcadas pelo monólogo e pela posição passiva dos alunos que nada entendem do que o mestre eloquente explica:

A menina de boina azul entregou a sua virgindade ao namorado que agora recusa casar com ela. $\mathrm{O}$ sargento do exército sonha com os galões de tenente e sofre porque não pode compreender equações do primeiro grau nem decorar as fórmulas de química. O senhor de cabelos grisalhos suporta em silêncio a vergonha de ter que frequentar aos quarenta anos um curso preparatório porque precisa dum diploma e precisa do diploma porque lhe é imprescindível ter uma profissão liberal a fim de ganhar dinheiro para sustentar a família numerosa.

$[\ldots]$

Mas nesse instante só uma coisa importa [ao professor]: a quantidade. Todas as outras necessidades empalidecem, recuam para segundo plano. Lá fora a cidade vive, os bondes e os autos rolam, os homens caminham e lutam, os dramas acontecem, há angústias

19. BilaC, Olavo. Poesia. São Paulo: Martins Fontes, 1996, p. 336. 
escondidas, gritos de dor e de contentamento, os poetas fazem versos à lua, os vaga-lumes passeiam pelos jardins, por onde vagam homens sem trabalho e sem rumo, nascem gênios e imbecis, mas o que importa para o professor Clarimundo é a quantidade. ${ }^{20}$

Percebe-se nesse trecho que os interesses dos alunos e os do professor são totalmente divergentes, sem que este se dê conta de que seus alunos estão em outro mundo. Essa distância entre os chamados homens de letras e o grosso da população - representada no trecho por vários setores sociais - é comentada por Paulo Prado no seu postscriptum ao Retrato do Brasil:

O analfabetismo das classes inferiores - quase de $100 \%$ - corre parelhas com a bacharelice romântica do que se chama a intelectualidade do país. Sem instrução, sem humanidades, sem ensino profissional, a cultura intelectual não existe, ou finge existir em semiletrados mais nocivos que a peste. Não se publicam livros, porque não há leitores, não há leitores porque não há livros. Ciência, literatura, arte — palavras cuja significação escapa a quase todos. Em tudo domina o gosto do palavreado, das belas frases cantantes, dos discursos derramados: ainda há poetas de profissão. ${ }^{21}$

Nota-se no texto de Paulo Prado, escrito entre 1926 e 1928, uma desilusão com o cenário cultural de nosso país, que ocasionaria um bloqueio à verdadeira intelectualidade e a qualquer projeto desenvolvimentista. Os resquícios do academicismo e do uso de um português "culto" - heranças culturais criticadas pelo modernismo de 22 - deitavam raízes profundas em nossa cultura. Em Caminhos Cruzados, outras duas personagens, também caricatas, o capitalista Teotônio Leitão Leiria e o dr. Armênio Albuquerque, manifestam esse "gosto do palavreado". Para eles, a ilustração e o conhecimento são expressos em um português destinado a poucos e cheio de preciosismos linguísticos. Porém, essas duas personagens se valem da escrita para posarem de homens cultos. Já Clarimundo vive num mundo à parte, quando usa palavras complexas é movido por uma concepção de arte, de escrita, de língua coerente com seu modo de vida: distante da realidade.

20. Verissimo, Erico. Caminhos cruzados, cit., p. 85.

21. Prado, Paulo. Retrato do Brasil: ensaio sobre a tristeza brasileira. 8. ed. São Paulo: Companhia das Letras, 1997. 
Assim, o telescópio do homem de Sírio - imagem criada para o futuro romance do professor - evidencia um dos seus principais problemas: o seu lunatismo, a sua alienação. Aliás, há outras personagens que também apresentam essa característica nos romances produzidos no período por Erico Verissimo. Em Clarissa, a personagem Amaro, um músico frustrado que virou funcionário de banco, é chamado pelo seu patrão de lunático. ${ }^{22}$ Já em Música ao longe, o principal intelectual de Jacarecanga, Leocádio Santarém, tem um telescópio e se diz membro de associações científicas. Com a morte de Leocádio, Vasco e Clarissa descobrem que o telescópio era falso e que não dava para ver nada com ele. $\mathrm{O}$ traço comum das três personagens é sua inadequação, sua solidão, sua incapacidade de diálogo autêntico com o Outro. Amaro tem consciência de seu isolamento - o que torna sua situação mais pungente. Leocádio posa de intelectual no ambiente tacanho de Jacarecanga e ao final ironiza a ignorância da população da cidade.

Ao contrário dessas duas personagens, Clarimundo não percebe sua desconexão com o mundo. Mundo este que aparece apenas no seu nome, pois o professor só consegue olhar para dentro, não consegue olhar para a realidade que o circunda nem na travessa das Acácias, nem no seu passeio de bonde, nem na sala de aula e muito menos na casa dos capitalistas onde dá aulas particulares. No entanto, como professor e pertencendo a um setor intermediário da sociedade, ele poderia ter uma visão mais ampla sobre vários aspectos sociais, e poderia ser o homem de Sírio. Lukács comenta essa escolha de personagens que representem o "caminho do meio" como um dos grandes achados da forma romance, pois essas personagens propiciam "a exposição da totalidade histórica". ${ }^{23}$ Erico expõe essa totalidade histórica acompanhando a trajetória de várias personagens com um narrador onisciente. As personagens caricatas, como Clarimundo, não conseguem construir uma concepção do seu lugar na sociedade. $\mathrm{O}$ efeito humorístico e crítico se dá pelo contraste entre aquilo que a personagem não vê e aquilo que os leitores podem ver conduzidos pelo narrador.

E a criação ficcional de Clarimundo, o homem de Sírio? Seria a representação de certo segmento da intelectualidade brasileira? Dos impasses da escrita naquele momento? Essa discussão não estaria representada pelo par Noel e Fernanda, considerando-se

\footnotetext{
22. Verissimo, Erico. Clarissa, cit., p. 30.

23. LukÁcs, Georg. O romance histórico. Tradução de Rubens Enderle. São Paulo: Boitempo, 2011. Lukács usa como exemplo do uso dessa técnica o romancista Walter Scott.
} 
que esta última é uma espécie de porta-voz das visões estéticas e literárias do autor, como afirmaram vários críticos?Comparando Clarimundo com o par Noel / Fernanda, pode-se perceber a complexidade escondida por trás do ridículo das atitudes do professor. Fernanda encarna um projeto utópico, a possibilidade de transformações sociais. Noel, o escritor avesso à realidade, é reorientado por Fernanda para que direcione seu olhar a outro tipo de literatura, que fosse voltada para os grandes debates sociais da época. Já o professor, ele está isolado. Natural do interior do estado, ele vivencia um período de profundas transformações, tem uma formação difusa, sobrevive à custa de vários empregos e ainda tem que achar tempo para seus projetos literários. Daí a sua atitude solitária, pois "sob o impacto da modernização, em meio à fragmentação que aliena, coisifica e esmaga, a atitude natural do sujeito que sobrevive (e que se sente esvaziado de si mesmo) é o recolhimento". ${ }^{24}$

Se parece improvável que Clarimundo escreva seu livro, tendo em vista as várias vezes que cancela o início da escrita, o romance termina com esse movimento de escrita, mas de um modo inusitado: pelo prefácio. Justamente pelo prefácio, pela parte não literária da obra, pela justificativa do ato de escrita que o professor inicia seu livro, coincidindo com o encerramento de Caminhos cruzados.

O prefácio serve para que o professor Clarimundo esclareça a natureza de seu livro, que não é apenas um romance, mas uma tentativa de compreender as grandes verdades do mundo. Claro que na escrita desse prefácio o professor revela seus cacoetes, como querer utilizar uma palavra difícil para denominar o seu prefácio: antelóquio. Mas essa atitude aparentemente banal e até mesmo risível da personagem - de querer iniciar a escrita de um livro pelo prefácio - relaciona-se com uma série de livros daquele período que tornaram o prefácio (ou notas dos autores) uma espécie de manifesto, de explicação necessária ao leitor sobre a especificidade da obra, sobre os posicionamentos políticos e ideológicos do autor e sobre o caráter de denúncia presente no livro. Isso pode ser observado na famosa nota de Jorge Amado a Cacau (1933): “Tentei contar nesse livro, com um mínimo de literatura para um máximo de honestidade, a vida dos trabalhadores das fazendas de cacau do sul da Bahia. Será um romance proletário?", ${ }^{25}$ que também acaba por indicar um caminho de interpretação para a obra.

24. Marques, Ivan. Cenas de um modernismo de província - Drummond e outros rapazes de Belo Horizonte. São Paulo: Editora 34, 2011.

25. Amado, Jorge. Cacau. São Paulo: Companhia das Letras, 2010. 
O caso de Erico Verissimo é peculiar, pois ele recorrera aos prefácios a posteriori para justificar as imperfeições e os problemas de livros publicados anteriormente, os fatos que motivaram a escrita, estabelecendo um diálogo com seus eventuais leitores e, principalmente, com seus críticos. Nas primeiras edições desses romances não havia justificativas de seu projeto autoral e nem considerações do autor sobre as condições de escrita. Ao lado disso, assinala-se a tendência de suas personagens também estarem envolvidas de alguma forma com a leitura ou com a escrita. Como observou Silviano Santiago: "Erico é certamente o romancista brasileiro que mais fez os seus personagens lerem livros. Praticamente todos os seus personagens são leitores e mantêm com os livros um relacionamento singular e interessante". ${ }^{26}$

Tal encenação da escrita e da leitura era recorrente naquele momento e não se tratava de algo apenas na obra do autor gaúcho, bastando lembrar o romance de estreia de Jorge Amado: O país do carnaval (1931). Nesse livro, uma das personagens, José Lopes, também escrevia um romance, que remetia de forma metalinguística ao livro de Jorge Amado, ${ }^{27}$ uma estratégia semelhante empregada posteriormente por Verissimo na construção da história do homem de Sírio dentro do romance Caminhos cruzados. Há, pois, aqui a história dentro da história: a onisciência desse narrador que observa à distância e conhece todos os movimentos das personagens de diferentes espaços da cidade é a onisciência do narrador de Caminhos cruzados. Ou seja: a moldura narrativa do projeto ficcional do professor Clarimundo é a chave de leitura da perspectiva adotada pelo narrador de Caminhos cruzados.

Essas constantes referências à escrita e à leitura serviam para debater as condições precárias em que o trabalho intelectual se desenvolvia no Brasil. Tais questões desdobradas pela ação das personagens são vistas criticamente pelo autor gaúcho em prefácios de novas edições do livro. Como se pode observar nos prefácios de Clarissa - quando Erico diz ter escrito seu livro durante os finais de semana - ou no de Música ao longe, escrito em menos de um mês para participar de um concurso.

Além das minhas funções de secretário da Revista do Globo, para aumentar a renda mensal eu redigia uma página feminina para o Correio do Povo e à noite traduzia do inglês

26. Santiago, Op. cit., p. 156.

27. Amado, Jorge. O país do carnaval. 38. ed. Rio de Janeiro: Record, 1980. 
novelas policiais para a Livraria Globo, de sorte que para minha própria literatura só me restavam - e assim mesmo nem sempre - os fins de semana.

Escrevi Clarissa em quinze tardes de sábado e uma boa dúzia de domingos, feriados e dias santos. O livro apareceu em novembro de 1933 numa coleção de volumes de pequeno formato, na qual havia uma estranha mistura, obras de Gogol e de Edgar Wallace, Puskhine e Fennimore Cooper. ${ }^{28}$

Esta história foi escrita em quinze ou vinte dias, especialmente para concorrer ao "Prêmio de Romance Machado de Assis", instituído em 1934 pela Cia. Editora Nacional de São Paulo. ${ }^{29}$

Fazia-se necessária a construção de uma nova imagem sobre o trabalho do intelectual. ${ }^{30}$ O escritor como o revelador de grandes verdades, como alguém distante do dia a dia era um modelo a ser superado. Deve-se destacar que esse imaginário achava solo fértil no Rio Grande do Sul, que fora fortemente marcado pelo Simbolismo, responsável por construir imagens do poeta-autor como um Assinalado "que povoa o mundo despovoado,/ de belezas eternas, pouco a pouco.... ${ }^{31}$ Naquela mesma década de 30, o poeta gaúcho Mario Quintana publicou o livro de sonetos Rua dos Cataventos (1938), em que a fusão de uma percepção sensorial do cotidiano propiciava a manutenção dessa herança simbolista, porém avançando para um lirismo moderno, que flagrava instantâneos da cidade que se modernizava, como se vê neste poema:

Na minha rua há um menininho doente.

Enquanto os outros partem para escola, Junto à janela, sonhadoramente,

Ele ouve o sapateiro bater sola.

28. Verissimo, Erico. Clarissa, cit., p. XVI.

29. Id., Música ao longe, s/n.

30. Nesse sentido, é interessante o depoimento de Dyonélio Machado sobre as condições de escrita de Os ratos. Este livro também foi escrito em vinte dias (Machado, Dyonélio. Os ratos. 21. ed. São Paulo: Ática, 1988).

31. Sousa, Cruz e. Últimos sonetos. 3. ed. Florianópolis: Editora da UFSC; Rio de Janeiro: Fundação Casa de Rui Barbosa, 1997. 
Ouve também o carpinteiro, em frente,

Que uma canção napolitana engrola.

E pouco a pouco, gradativamente,

O sofrimento que ele tem se evola...

Mas nesta rua há um operário triste:

Não canta nada na manhã sonora

E o menino nem sonha que ele existe.

Ele trabalha silenciosamente...

E está compondo este soneto agora,

Pra alminha boa do menino doente... ${ }^{32}$

A imagem do intelectual nesse poema é outra: um operário triste, que compõe seus poemas a partir dos temas que estão próximos a ele. O poeta observa aquilo que o olho alcança (na minha rua) e não universos insondáveis. Os elementos simbolistas se mantêm enquanto forma e seleção vocabular, mas a temática é outra.

Em Música ao longe, publicado no mesmo ano de Caminhos cruzados, o projeto de desconstrução da imagem do intelectual tem sua continuidade com Paulo Madrigal, pseudônimo de um poeta que é também caixeiro-viajante, cujo nome real é o inusitado Anfilóquio Bonfim, um homem gordo e que vende Gargarol. Clarissa, que conhecia a obra de Paulo Madrigal, se desilude com o poeta-caixeiro, mas percebe seu problema: o excesso de fantasia e de idealização na construção da imagem do escritor. O poeta, que acumula a função de caixeiro-viajante, denuncia a precariedade de se sobreviver da literatura, mas traz também uma dimensão humana: o poeta como um indivíduo comum, que também precisa ganhar sua vida..$^{33}$

\footnotetext{
32. Id., p.11.

33. Marisa Lajolo comenta sobre a postura dessacralizada de Erico Verissimo em relação ao fazer literário, usando muitas vezes metáforas comerciais e de mercado para tratar de aspectos relativos à publicação de seus livros (LAJOLO, Marisa. "Uma trajetória cultural rara na tradição brasileira”. In: Caderno de pauta simples - Erico Verissimo e a crítica literária. Organização de Maria da Glória Bordini. Porto Alegre/Rs: Instituto Estadual do Livro: 2005, pp. 129-42).
} 
A não especialização do escritor num país de poucos leitores e de um sistema literário debilitado coincide com a precariedade do trabalho do professor Clarimundo, que tem de se desdobrar entre mil afazeres para sobreviver, como se percebe neste trecho:

Clarimundo coordena ideias: sábado, Francês para o filho do cel. Pedrosa, Matemática e Latim no curso noturno e... - com as mãos suspensas, úmidas, pingando, aproximase para o horário que está colado à parede - Português para filho do desembargador Floriano. Bom. ${ }^{34}$

Clarimundo leciona matemática, latim, francês, inglês. Trabalha em uma escola noturna, dá aulas particulares e ainda acha tempo para publicar em periódicos. Imagem bastante semelhante à do próprio Erico, que naquele período acumulava funções como editor de revista, tradutor, apresentador de programa infantil de rádio e escritor.

Num país de poucos leitores como o Brasil, as figuras do professor e do escritor são bastante emblemáticas. Seus interlocutores, alunos e leitores, não costumam ser oriundos de uma cultura letrada e projetam com naturalidade um distanciamento em relação aos representantes dessa cultura: "Atrás da figura do professor está a escola e todas as relações próprias da instituição: a autoridade, o superior, o culto, aquele que diz como deve ser feito". ${ }^{35}$ Os alunos do professor Clarimundo vinham em sua maioria de setores sociais que passaram a ter acesso à escola apenas recentemente. Outros bens culturais como a leitura também eram novidade para esse setor médio-baixo da sociedade.

É nesse cenário que o escritor e o professor, muitas vezes oriundos de segmentos emergentes da sociedade, estabelecem um papel de ligação entre diversos estratos sociais. Essa questão deve ser observada: Fernanda e Clarimundo travam relações com os dois espaços principais representados em Caminhos cruzados - o beco das Acácias e o bairro nobre do Moinho de Ventos em Porto Alegre. Coincidentemente, os dois são professores.

São também essas duas personagens que travam um contato mais próximo com o mundo da técnica. Fernanda, com desenvoltura, datilografa as cartas de Leitão Leiria. Clarimundo, de maneira ambígua, se comporta como uma máquina a executar suas funções de maneira nada crítica, projetando um romance em que um telescópio desem-

34. Verissimo, Caminhos cruzados, cit., p. 4.

35. BRITto, Luiz Percival Leme. "Em terra de surdos-mudos (um estudo sobre as condições de produção de textos escolares)”. In: GerAldi, João Wanderley. O texto na sala de aula. 5. ed. São Paulo: Ática, 2011, p. 120. 
penha um papel essencial, mas tem profundas dificuldades de lidar com a técnica, inclusive temendo-a.

Quanto ao comportamento maquinal, Clarimundo é visto pela sua vizinhança como uma espécie de homem-relógio. A saída do professor de casa assinala para os moradores da travessa das Acácias que é meio-dia e cinquenta. A rotina de Clarimundo é extremamente rígida, não se permitindo atrasos, marcando no relógio o tempo exato dedicado à leitura de estudo (quarenta minutos diários). No entanto, esse homem-relógio é arredio aos avanços tecnológicos. Fora do ambiente doméstico, fora da sala de aula, Clarimundo passa por uma verdadeira epopeia do homem moderno para chegar ao trabalho, seus inimigos: o guarda-chuva e o bonde.

Clarimundo aceita Einstein, conhece Mecânica, louva o Progresso em teoria, mas aborrece-o na prática e tem um grande horror às máquinas. $\mathrm{E}$ as máquinas lhe são tanto mais horrorosas, quanto maiores forem os perigos que oferecem à vida do prof. Clarimundo e dos outros humanos. Admira a Aeronáutica em teoria, mas jamais entra num avião. Detesta o bonde mas utiliza-se dele com uma cautelosa relutância. E apesar de já estar quase convencido das vantagens do rádio, ainda não se decidiu a comprar um receptor. ${ }^{36}$

Todos se valem da técnica sem saber como esta funciona. Esse é o questionamento do professor que prefere os cálculos aos objetos gerados por esses cálculos.

A modernização de Porto Alegre estava a todo vapor. ${ }^{37}$ Indícios dessa modernização podem ser vistos em Os ratos, de Dyonélio Machado. É de se estranhar que um personagem como Naziazeno Barbosa se locomova com tanta facilidade pela cidade, enquanto Clarimundo se sinta tão inadaptado. Ambas as personagens vêm do interior, mas a personagem de Dyonélio Machado que esboçava uma saudade do pampa se virava muito bem com os artefatos modernos. Clarimundo, por sua vez, não chega a esboçar essa nostalgia de suas raízes. Parece estar adaptado à sua rotina, um verdadeiro "boi de canga", como se diria no Rio Grande do Sul: metido no seu trabalho e acostumado às condições precárias de vida. Aqui também se encontra um ponto de contato entre Amaro, personagem de Clarissa, e Clarimundo. O músico que virara funcionário de banco sentia-se oprimido pelo mundo da técnica e do capital:

36. Verissimo, Erico. Caminhos cruzados, cit., p. 40.

37. Cruz, Cláudio. Literatura e cidade moderna - Porto Alegre 1935. Porto Alegre: EDIPUCRS, 1994, pp. 57-88. 
Quando terminará o conflito? Conflito com a vida, com os homens que andam pela vida a se magoarem uns aos outros, a disputar lugares aos encontrões e cotoveladas? Cada dia que passa é uma tortura que se repete. O expediente do banco, o tá-tá-tá das máquinas de escrever, os cavalheiros que discutem juros de mora, taxas, câmbios; contínuos que passam com pastas gordas de papéis cheios de algarismos; e homens inclinados sobre as carteiras, escrevendo, registrando, calculando... ${ }^{8}$

Amaro, porém, sofre ainda de outro problema: é incapaz de agir, vive num mundo de sonhos e de projetos que não se realizam. Aos quarenta anos, é um homem envelhecido, preso no seu mundo, como o peixe Pirolito, que dera de presente a Clarissa, em seu aquário. As duas personagens - Amaro e Clarissa - formam um par de opostos: o velho e o novo, o movimento e a inércia.

Já Clarimundo não forma par com nenhuma outra personagem. Seu trânsito pela cidade é alienado e solitário. Seu trabalho é feito de maneira burocrática e sem a interação de seus alunos. Na sua condição de homem de 30, o professor traz em si as tensões daquela geração, mas sem ter consciência delas. As tensões entre o EU e o MUNDO apontadas por Candido na poesia de Drummond aparecem pela metade em Clarimundo. ${ }^{39} \mathrm{O}$ foco de seu telescópio não está no MUNDO, mas no seu próprio EU, que não consegue estabelecer contato com o Outro. Seu nome é "apenas uma rima e não uma solução" para os impasses que vivencia e que está muito longe de perceber.

Marcos Scheffel é professor adjunto na Faculdade de Educação da Universidade Federal do Rio de Janeiro e autor de Estações de passagem da ficção de Lima Barreto [Annablume, 2012].

38. Verissimo, Erico. Clarissa, cit., p. 30.

39. CANDIDO, Antonio. Inquietudes na poesia de Drummond. In: Vários escritos. $5^{\mathrm{a}}$ ed. Rio de Janeiro: Ouro Sobre Azul, 2011. p. 69-99. 